\title{
Structures of an extradiol catechol dioxygenase - C23064, from 3-nitrotoluene degrading Diaphorobacter sp. strain DS2 in substrate-free, substrate-bound and substrate analog-bound states
}

\author{
Keerti Mishra ${ }^{1}$ (D), Chetan Kumar Arya ${ }^{1}$ (D), Ramaswamy Subramanian ${ }^{2}$ (D) and \\ Gurunath Ramanathan $^{1, *}$ (D) \\ ${ }^{1}$ Department of Chemistry, Indian Institute of Technology Kanpur, Kanpur, Uttar Pradesh, INDIA -208016, and ${ }^{2}$ Technologies \\ for the Advancement of Science, Institute of Stem Cell Biology and Regenerative Medicine, NCBS, GKVK, Bangalore, \\ Karnataka, India. \\ Correspondence. Email: gurunath@iitk.ac.in
}

(Received 26 June 2020; Revised 07 September 2020; Accepted 09 September 2020)

\begin{abstract}
This manuscript reports structure-function studies of Catechol 2,3-dioxygenase (C23O64), which is the second enzyme in the metabolic degradation pathway of 3-nitrotoluene by Diaphorobacter sp. strain DS2. The recombinant protein is a ring cleavage enzyme for 3-methylcatechol and 4-methylcatechol products formed after dioxygenation of the aromatic ring. Here we report the substrate-free, substrate-bound, and substrate-analog bound crystal structures of C23O64. The protein crystallizes in the P6(2)22 space-group. The structures were determined by molecular replacement and refined to resolutions of 2.4, 2.4, $2.2 \AA$, respectively. A comparison of the structures with related extradiol dioxygenases showed 22 conserved residues. A comparison of the active site pocket with catechol 2,3-dioxygenase (LapB) from Pseudomonas sp KL28 and homoprotocatechuate 2,3-dioxygenase (HPCD) from Brevibacterium fuscum shows significant similarities to suggest that the mechanism of enzyme action is similar to HPCD.
\end{abstract}

Keywords: Catechol 2,3-dioxygenase; Diaphorobacter sp. strain DS2; extradiol dioxygenases; aromatic ring cleavage; Mononuclear iron-containing enzymes

\section{Introduction}

Microbes degrade aromatic compounds aerobically using well-established pathways. Most reported aerobic degradation pathways proceed through the dioxygenation of the aromatic ring forming catechollike intermediates (Mason \& Cammack, 1992). Subsequently, the thermodynamically stable aromatic ring is cleaved to generate products that can enter the Krebs cycle directly for complete aerobic degradation. The dihydroxylated catechol ring is either cleaved in an intradiol manner (Hayaishi et al., 1955) or an extradiol fashion (Kojima et al., 1961). The extradiol dioxygenase class of enzymes has three distinct evolutionary family trees based on diverse substrate preferences (Vilchez-Vargas et al., 2010). Since the first structure of an extradiol dioxygenase 2,3-dihydroxybiphenyl 1,2-dioxygenase (DHBD) from Pseudomonas sp. LB-400 (Han et al., 1995), numerous studies have elucidated the mechanism for these classes of enzymes (Kovaleva \& Lipscomb, 2008). The structures typically contain

\footnotetext{
(C) The Author(s), 2020. Published by Cambridge University Press. This is an Open Access article, distributed under the terms of the Creative Commons Attribution licence (http://creativecommons.org/licenses/by/4.0/), which permits unrestricted re-use, distribution, and reproduction in any medium, provided the original work is properly cited.
} 
two repeating $\beta \alpha \beta \beta \beta$ motifs in a domain forming a funnel-shape to accommodate the 2-His-1-carboxylate active site residues that are bound to $\mathrm{Fe}(\mathrm{II})$ or $\mathrm{Mn}(\mathrm{II})$ metal ions as a facial triad (Kita et al., 1999). Mostly, no cofactor other than the metal ion is present in these reported structures, and the electron transfer occurs primarily to the bound substrate via the metal to the bound oxygen, activating them both for the reaction. Our study enriches the structural aspect of a catechol 2,3-dioxygenase of a Diaphorobacter sp. strain DS2 (Singh \& Ramanathan, 2013), which is a non-motile gram-negative bacterium that specifically degrades 3-nitrotoluene and can use it as the sole nitrogen and energy source. We report the crystal structures of recombinant $\mathrm{C} 23 \mathrm{O} 64$ catechol dioxygenase enzyme in three forms: ligand-free, 4-methylcatechol-bound (4-MC), and 3-fluorocatechol-bound (3FA).

\section{Objective}

Elucidate the structure of C23O64 (catechol dioxygenase) from Diaphorobacter sp. strain DS2 using $\mathrm{X}$-ray crystallography. The structure was then compared with other extradiol enzyme structures to infer a reasonable reaction mechanism for $\mathrm{C} 23 \mathrm{O} 64$.

\section{Methods}

The supporting information contains all the specific methods used in this manuscript.

Table 1. Structure solution and refinement values in parentheses are for the outer shell.

\begin{tabular}{|c|c|c|c|}
\hline & Substrate free & C23064-3FA & C23064-4MC \\
\hline PDB-ID & $5 Z S Z$ & $5 Z S X$ & $5 \mathrm{ZNH}$ \\
\hline Resolution range $(\AA)$ & $46.7-2.4(2.48-2.4)$ & $47.9-2.2(2.28-2.2)$ & $46.5-2.4(2.49-2.4)$ \\
\hline Completeness (\%) & $99.88(100.00)$ & $98.89(89.27)$ & $99.81(100.00)$ \\
\hline No. of reflections, working set & $14,283(1388)$ & $18,244(1606)$ & $14,254(1402)$ \\
\hline No. of reflections, test set & $706(71)$ & $932(85)$ & $716(77)$ \\
\hline Final $R_{\text {cryst }}$ & $0.21(0.28)$ & $0.19(0.44)$ & $0.19(0.21)$ \\
\hline Final $R_{\text {free }}$ & $0.24(0.30)$ & $0.24(0.50)$ & $0.24(0.34)$ \\
\hline \multicolumn{4}{|l|}{ No. of non-H atoms } \\
\hline Protein & 2,285 & 2,454 & 2,454 \\
\hline Ligand & 2 & 26 & 22 \\
\hline Water & 25 & 64 & 33 \\
\hline Total & 2,312 & 2,544 & 2,509 \\
\hline \multicolumn{4}{|l|}{ R.m.s. deviations } \\
\hline Bonds $(\AA ̊)$ & 0.003 & 0.004 & 0.008 \\
\hline Angles $\left({ }^{\circ}\right)$ & 0.91 & 1.00 & 1.25 \\
\hline \multicolumn{4}{|l|}{ B-factor $\left(\AA^{2}\right)$} \\
\hline Overall & 56.61 & 49.65 & 52.68 \\
\hline Protein & 56.65 & 49.60 & 52.71 \\
\hline Ligand & 73.41 & 61.47 & 56.73 \\
\hline \multicolumn{4}{|l|}{ Ramachandran plot } \\
\hline Most favored (\%) & 97.59 & 97.76 & 96.79 \\
\hline Allowed (\%) & 2.41 & 2.24 & 3.21 \\
\hline
\end{tabular}



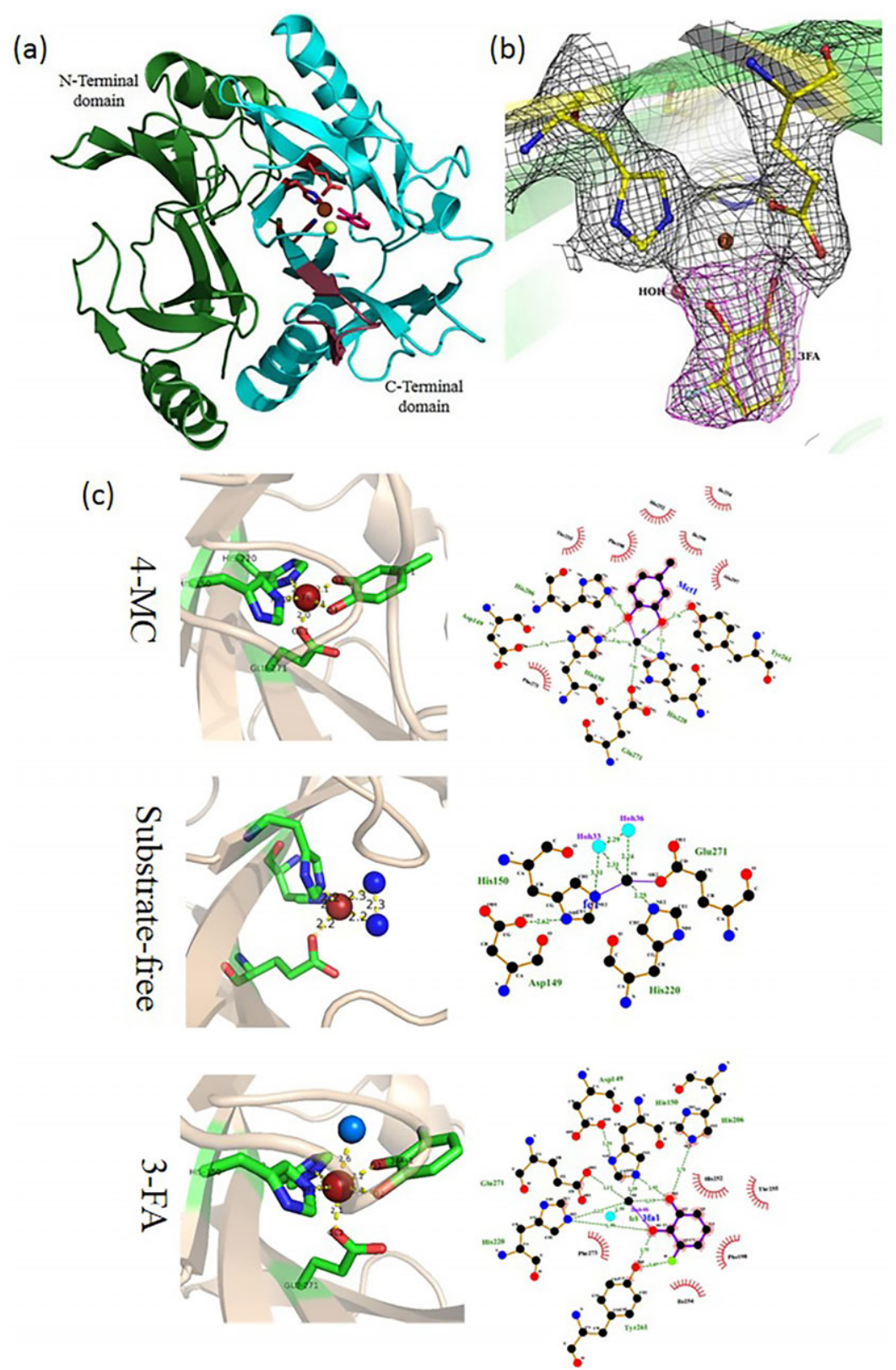

Fig. 1. (a) A monomer of $\mathrm{C} 23064$ in 3-fluorocatechol bound crystal. The active site is present in the C-terminal domain (b) Diagram for the active site of the 3-fluorocatechol bound protein, the ligand was omitted from the structure, and a simulated annealed omit map (to remove bias) was calculated in the region of the ligand using Phenix. The grey map is the $(2 \mathrm{Fo}-\mathrm{Fc})$ map at $1^{\star} \mathrm{RMS}$ around the active site. In Magenta is the (Fo- $\mathrm{Fc}$ ) at $1^{\star}$ Sigma. The position of the refined 3FA fits the difference electron density nicely. The electron density for the water molecule bound to Fe was also omitted and is visible in the structure. The figure was made with Pymol (c) Active site of the protein in different crystals showing different coordination geometries around the metal ion and two-dimensional representation of substrate interaction in the active site pocket using LIGPLOT (i) In the 4-methylcatechol bound protein, the Fe is having distorted square pyramidal geometry (ii) In the substratefree structure, the active site Fe is bound to two water molecules while exhibiting a distorted trigonal bipyramidal geometry (iii) In the 3-fluorocatechol bound protein, the Fe is coordinated to the substrate and one water molecule, displaying a distorted octahedral geometry. 


\section{Results and discussion}

The diamond-shaped protein crystals appeared after 3 to 4 days at $18^{\circ} \mathrm{C}$ (Fig. S2). The crystals formed in $0.2 \mathrm{M} \mathrm{MgCl}_{2}, 0.1 \mathrm{M}$ HEPES sodium salt pH-7.5, and 30\% v/v PEG-400 was soaked in substrate solution. Aerobic conditions were used for crystallization and soaking experiments. Therefore, the proteins in the crystal were enzymatically inactive, due to oxidation of Fe (II) to Fe (III) at the active site.

The crystal structure was solved using molecular replacement methods. Table 1 shows the results generated after iterative refinements. An asymmetric unit contains a 314 amino acid monomer, whereas based on results from size exclusion chromatography, the protein is tetrameric in solution (Fig. S4).

Crystal contacts form the biologically active tetramer. Like the other reported catechol dioxygenases, the $\mathrm{C} 23 \mathrm{O} 64$ protein is also a two-domain protein. It has a repeating $\beta \alpha \beta \beta \beta$ motif forming an antiparallel $\beta$ barrel structure in each $\mathrm{N}$ - and $\mathrm{C}$-terminal domains. The active site is present in the C-terminal domain within the barrel-shaped structure (Fig 1). The electron density map of the substrate-free crystal did not show a good density for 294-314 amino acid residues, due to disorder in the absence of the substrate.

The active-site contains His150, His220, and Glu271 bound to the metal ion in a facial triad manner. In the active-site of the substrate-free $\mathrm{C} 23 \mathrm{O} 64$, the penta-coordinated Fe was bound to two water molecules in a trigonal bipyramidal coordination geometry. In the 4-methylcatechol-bound form, the Fe is penta-coordinated with a square pyramidal geometry. In contrast, in 3-fluorocatechol-bound

(a)

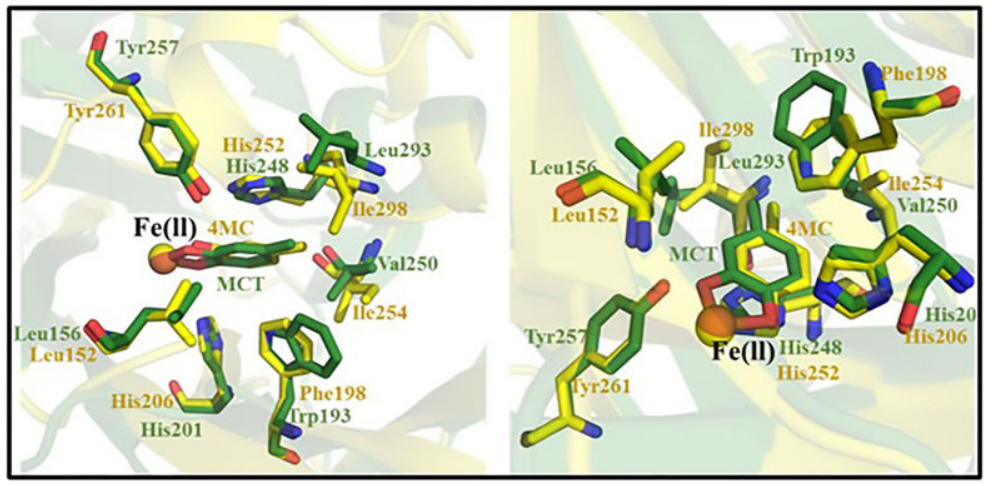

(b)

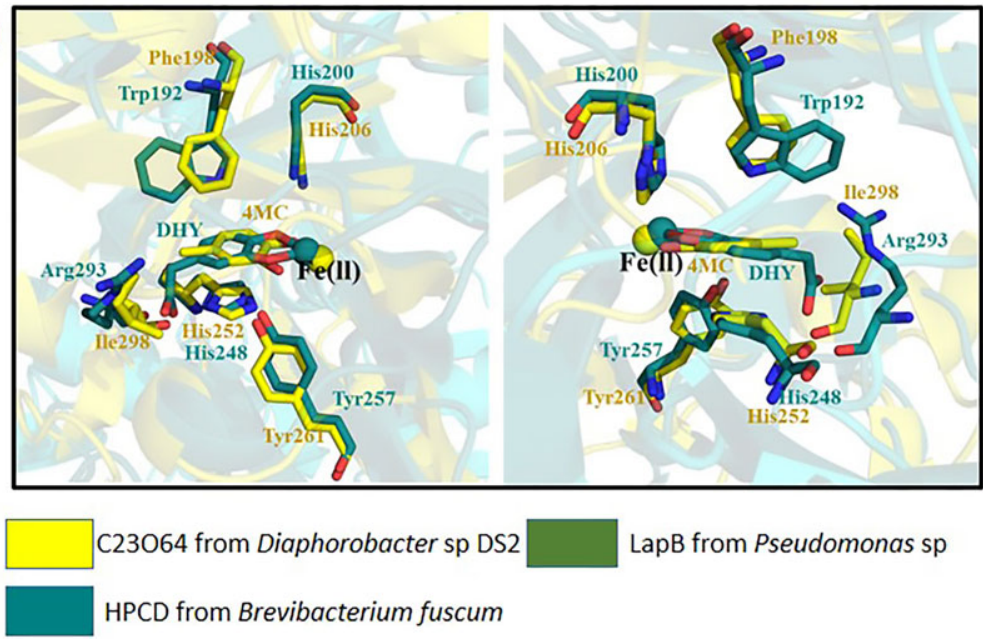

Fig. 2. Comparison of the active site pocket of catechol 2,3-dioxygenase (C23064) from Diaphorobacter sp. strain DS2 (5ZNH) with (a) LapB from Pseudomonas sp. KL28 (3HPY) and (b) HPCD from Brevibacterium fuscum (1Q0C). The metal binding facial triad residues (His His Glu) has been hidden in the active site pocket for clarity. 


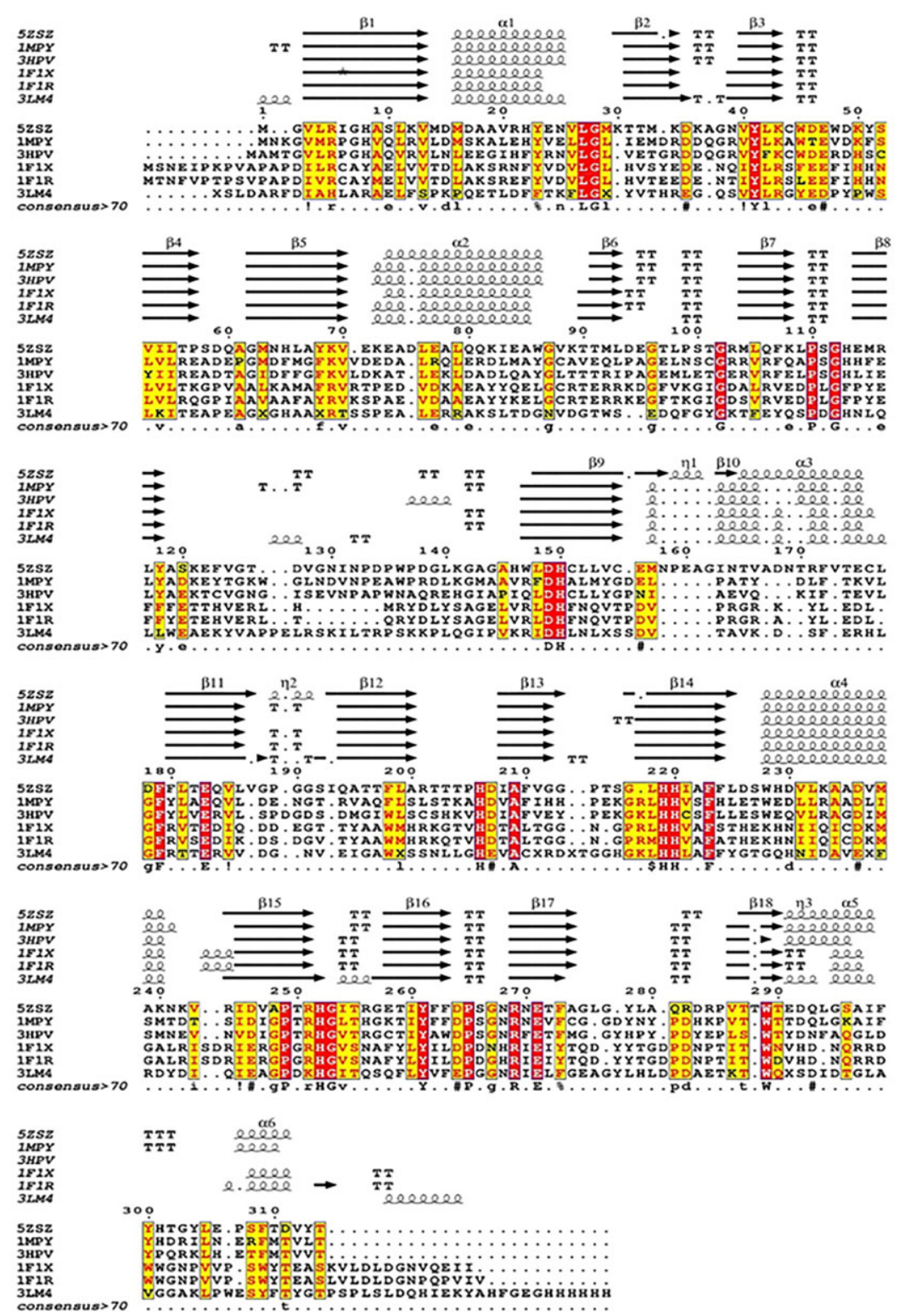

Fig. 3 Structure-based alignment of C23064 from Diaphorobacter sp. strain DS2 5ZSZ and selected type 1 extradiol dioxygenases that are reported. 1MPY from Pseudomonas sp. MT2 (43\% sequence identity), 3HPV is LapB from Pseudomonas sp. KL28 (42\%), 1F1X is HPCD from Brevibacterium fuscum, 1F1R is HPCD from A. globiformis, and 3LM4 is DHBN from Rhodococcus has less than $28 \%$ sequence identity

structure, the active-site iron is hexa-coordinate with the substrate and a water molecule in a distorted octahedral geometry (Fig. 1). A comparison of the active-site pocket in these three forms of C23O64, revealed changes in His252, Ile254, and Thr255 side chains with an RMSD of $0.393 \AA$ (Fig. S3).

A comparison of the active sites of C23O64 with LapB from Pseudomonas sp KL28, having approximately $42 \%$ sequence identity, revealed three differences. The residues F198, I298, and I254 in C23O64 replace W193, L293, and V250 from $L a p B$, respectively. These substitutions provide a better binding pocket for 4-substituted catechols in C23O64 through hydrophobic interactions with I254 and I298. Another significant comparison with HPCD from Brevibacterium fuscum whose sequence identity 
is $28 \%$ (RMSD $1.98 \AA$ ) suggests that residues W192, R292 from HPCD replace F198 and I298 in the active site pocket of $\mathrm{C} 23 \mathrm{O} 64$. These amino acid sidechains play a crucial role in accommodating catechol and not homoprotocatechuate in the case of $\mathrm{C} 23 \mathrm{O} 64$. The amino acid side chain substitutions explain the inactivity of $\mathrm{C} 23 \mathrm{O} 64$ to 2,3-dihydroxybenzoic acid, and 3,4-dihydroxybenzoic acid as the smaller active site pocket cannot accommodate $-\mathrm{COO}^{-}$group. The $\mathrm{C} 23 \mathrm{O} 64$ active-site also lacks ionic interactions provided by R292 in HPCD. The sequence and structure comparisons present strong evidence that explains the difference in binding sites for the substrate accommodation. Despite having less than $28 \%$ sequence identity, the similarity in the active site pocket residues (Fig. 2) suggests a similar reaction mechanism (Kovaleva \& Lipscomb, 2007).

Sequence comparison of $\mathrm{C} 23 \mathrm{O} 64$ with other reported extradiol dioxygenases (Fig. 3) shows that it is indeed a type I extradiol dioxygenase. All these have 22 strictly conserved residues to play essential structural and functional roles. Where the metal binding H150, H220, E271 and H206 (Kovaleva et al., 2015), Y261 (Kovaleva \& Lipscomb, 2012) play key functional role, others determine substrate specificity and maintain structural integrity of the enzyme.

Acknowledgements. KM thanks CSIR India for Junior and Senior research fellowship. We would like to thank Dr. Deepak Singh from IITK for isolating and characterizing the Diaphorobacter sp strain DS2, and Dr. Vinod Nayak for helping with Phenix Suite.

Conflicts of Interest. None.

Author Contributions. K.M, R.G., S.R. designed the experiment. K.M. and C.A. did the experiments. K.M. analyzed the data and wrote the paper with support from R.G. and S.R.

Funding Information. The work has been supported by Indo-Swedish grant (S.R., BT/IN/SWEDEN/41/SR/2013); DBT (S.R., BT/PR5081/INF/156/2012, BT/PR12422/MED/31/287/214, BT/INF/22/SP22660/2017) and Council of Scientific and Industrial Research (K.M., 09/092(0869)/2013-EMR-I).

Supplementary Materials. To view supplementary material for this article, please visit http://dx.doi.org/10.1017/exp.2020.50.

\section{References}

Han, S., Eltis, L. D., Timmis, K. N., Muchmore, S. W., \& Bolint, J. T. (1995). Crystal structure of the biphenyl-cleaving extradiol dioxygenase from a PCB-degrading peudomonad. Science, 270, 976-980.

Hayaishi, O., Katagiri, M., \& Rothberg, S. (1955). Mechanism of the pyrocatechase reaction. Journal of the American Chemical Society, 77, 5450-5451.

Kita, A., Kita, S.-I., Fujisawa, I., Inaka, K., Ishida, T., Horiike, K., Nozaki, M., \& Miki, K. (1999). An archetypical extradiolcleaving catecholic dioxygenase: the crystal structure of catechol 2,3-dioxygenase (metapyrocatechase) from Pseudomonas putida mt-2. Structure, 7, 25-34.

Kojima, Y., Itada, N., \& Hayaishi, O. (1961). Metapyrocatechase: a new catechol-cleaving enzyme. Journal of Biological Chemistry, 236, 2223-2228.

Kovaleva, E. G., \& Lipscomb, J. D. (2007). Crystal structures of $\mathrm{Fe}^{2+}$ dioxygenase superoxo, alkylperoxo, and bound product intermediates. Science, 317, 453-457.

Kovaleva, E. G., \& Lipscomb, J. D. (2008). Intermediate in the O-O bond cleavage reaction of an extradiol dioxygenase. Biochemistry, 47, 11168-11170.

Kovaleva, E. G., \& Lipscomb, J. D. (2012). Structural basis for the role of tyrosine 257 of homoprotocatechuate 2,3-dioxygenase in substrate and oxygen activation. Biochemistry, 51, 8755-8763.

Kovaleva, E. G., Rogers, M. S., \& Lipscomb, J. D. (2015). Structural basis for substrate and oxygen activation in homoprotocatechuate 2,3-dioxygenase: roles of conserved active site histidine 200. Biochemistry, 54, 5329-5339.

Singh, D., \& Ramanathan, G. (2013). Biomineralization of 3-nitrotoluene by diaphorobacter species. Biodegradation, 24, 645-655.

Vilchez-Vargas, R., Junca, H., \& Pieper, D. H. (2010). Metabolic networks, microbial ecology and 'omics' technologies: towards understanding insitu biodegradation processes. Environmental Microbiology, 12, 3089-3104.

Cite this article: Mishra K, Arya CK, Subramanian R, Ramanathan G (2020). Structures of an extradiol catechol dioxygenase C23O64, from 3-nitrotoluene degrading Diaphorobacter sp. strain DS2 in substrate-free, substrate-bound and substrate analog-bound states Experimental Results, 1, e48, 1-9. https://doi.org/10.1017/exp.2020.50 


\title{
Peer Reviews
}

\author{
Reviewing editor: Dr. Ioannis Pavlidis
}

University of Crete, Rethimno, Greece, 74100

This article has been accepted because it is deemed to be scientifically sound, has the correct controls, has appropriate methodology and is statistically valid, and met required revisions.

doi:10.1017/exp.2020.50.pr1

Review 1: Structures of an extradiol catechol dioxygenase- C23064, from 3-nitrotoluene degrading Diaphorobacter sp. strain DS2 in substrate-free, substrate-bound and substrate analog-bound states

Reviewer: Prof. Michail Kokkinidis

Date of review: 19 August 2020

(c) The Author(s), 2020. Published by Cambridge University Press This is an Open Access article, distributed under the terms of the Creative Commons Attribution licence (http://creativecommons.org/licenses/by/4.0/), which permits unrestricted re-use, distribution, and reproduction in any medium, provided the original work is properly cited.

Conflict of interest statement. Reviewer declares none

Comments to the Author: This article is acceptable for publication after minor revisions, because it is scientifically sound, has the appropriate methodology, is statistically valid, and enriches our understanding of the structure-function relationships of extradiol dioxygenases. Necessary revisions: The key aspects of crystallization, structure determination and refinement should be moved from the Supplementary Information to the Main Text (Methods). The roles of the conserved residue motifs from Fig. 3 in structure-function relationships should be briefly discussed. In Fig. 1c, all structures should be shown in the same orientation (same projection), so they can be directly compared. There is a problem with residue numbering in Fig. 2, e.g. His151 should probably be His150. Check all residue numbering for consistency throughout the paper. The labels His151, His220 and Glu271 should be removed from Fig. 2, as the clarification in the figure caption is sufficient, UNLESS these residues change their conformations in the different structures, in which case also these residues and their side chains should be displayed. In Fig. S2 each monomer should be colored with a unique color. Displaying local and crystallographic symmetry elements that produce the tetramer in Fig. S2, would enhance our understanding of the assembly of the complete molecule.

\section{Score Card}

Presentation 
Does the abstract correctly embody the content of the article? (25\%)

Does the introduction give appropriate context? (25\%)

Is the objective of the experiment clearly defined? (25\%)

Analysis

Does the discussion adequately interpret the results presented? (40\%)

Is the conclusion consistent with the results and discussion? (40\%)

Are the limitations of the experiment as well as the contributions of the experiment clearly outlined? (20\%) 


\title{
Review 2: Structures of an extradiol catechol dioxygenase- C23064, from 3-nitrotoluene degrading Diaphorobacter sp. strain DS2 in substrate-free, substrate-bound and substrate analog-bound states
}

Reviewer: Dr. Jan Muschiol

GEOMAR, Ocean Ecosystem Biology, Düsternbrooker Weg 20, Kiel, Germany, 24105

Date of review: 29 July 2020

\begin{abstract}
(c) The Author(s), 2020. Published by Cambridge University Press This is an Open Access article, distributed under the terms of the Creative Commons Attribution licence (http://creativecommons.org/licenses/by/4.0/), which permits unrestricted re-use, distribution, and reproduction in any medium, provided the original work is properly cited.
\end{abstract}

Conflict of interest statement. Reviewer declares none

Comments to the Author: The authors of the present manuscript present three different structures of a catechol dioxygenase derived from Diaphorobacter sp. DS2. The results presented include crystal conditions as well as structure solution and refinement statistics. The three different structures were deposited in the PDB database and the PDB codes are given. In summary, this is a scientifcally sound manuscript. I have only three minor comments: 1 . In the abstract the authors claim to report a structurefunction study. Im my opinion the authors rather reported on structures only instead. 2. The authors claim that the protein is tetrameric in solution based on size exclusion chromatography, but don't present evidence for this. It would be good to add the SEC chromatogram to the results. 3. To increase reproducibility, please add a GenBank or UniProt accession number for the cloned gene/protein. Furthermore, it is unclear whether the gene was cloned from the original Diaphorobacter sp. DS2 or whether a synthetic codon optimized gene was used.

\section{Score Card}

Presentation

Is the article written in clear and proper English? (30\%)

Is the data presented in the most useful manner? (40\%)

Does the paper cite relevant and related articles appropriately? (30\%)

\section{Context}

Does the abstract correctly embody the content of the article? (25\%)

Does the introduction give appropriate context? (25\%)

Is the objective of the experiment clearly defined? (25\%)

Analysis

Are the limitations of the experiment as well as the contributions of the experiment clearly outlined? (20\%) 